\title{
Antifungal Activities of R-135853, a Sordarin Derivative, in Experimental Candidiasis in Mice

\author{
Yasuki Kamai, ${ }^{1 *}$ Masayo Kakuta, ${ }^{1}$ Takahiro Shibayama, ${ }^{2}$ Takashi Fukuoka, ${ }^{1}$ \\ and Shogo Kuwahara ${ }^{3}$ \\ Sankyo Co., Ltd., Shinagawa-ku, and Toho University School of Medicine, Ohta-ku, ${ }^{3}$ Tokyo, Japan
} \\ Biological Research Laboratories ${ }^{1}$ and Drug Metabolism and Pharmacokinetics Research Laboratories, ${ }^{2}$
}

Received 10 June 2004/Returned for modification 1 August 2004/Accepted 8 September 2004

\begin{abstract}
The activities of R-135853, a novel sordarin derivative that possesses a 1,4-oxazepane ring moiety, were evaluated in vitro and in vivo. R-135853 exhibited potent in vitro activities against Candida albicans (fluconazole-susceptible strains), Candida glabrata, Candida tropicalis, and Cryptococcus neoformans, with MICs at which $90 \%$ of isolates were inhibited of $0.03,1,0.5$, and $0.5 \mu \mathrm{g} / \mathrm{ml}$, respectively. $\mathrm{R}-135853$ also exhibited potent activities against fluconazole-susceptible dose-dependent and fluconazole-resistant strains of $C$. albicans, with MICs ranging from 0.03 to $0.06 \mu \mathrm{g} / \mathrm{ml}$. However, R-135853 exhibited weak or no activity against Candida parapsilosis, Candida krusei, and Aspergillus spp. R-135853 exhibited dose-dependent efficacy against experimental murine hematogenous candidiasis induced by $C$. albicans when it was administered by both the subcutaneous and the oral routes and reduced viable cell counts in the kidneys significantly when it was administered at $50 \mathrm{mg} / \mathrm{kg}$ of body weight/dose (administration three times a day). In this model, R-135853 also exhibited dose-dependent efficacy by single oral administration. Subcutaneous administration of R-135853 exhibited dose-dependent efficacy against experimental murine esophageal candidiasis induced by fluconazoleresistant $C$. albicans, against which fluconazole at $50 \mathrm{mg} / \mathrm{kg} / \mathrm{dose}$ was ineffective, and reduced viable cell counts in the esophagus significantly when it was administered at 10 and $50 \mathrm{mg} / \mathrm{kg} / \mathrm{dose}$. R-135853 eradicated $C$. albicans from the esophagi of one and four of five mice when it was administered at 10 and $50 \mathrm{mg} / \mathrm{kg} / \mathrm{dose}$, respectively. These results suggest that $R-135853$ is promising for the treatment of disseminated or mucosal candidiasis, including fluconazole-refractory infections.
\end{abstract}

The risk of opportunistic fungal infections is greatly increasing in patients who are immunocompromised due to cancer chemotherapy, organ or bone marrow transplantation, or human immunodeficiency virus infection (18). Candida albicans is the organism most often associated with both mucosal and hematogenously disseminated infections (4, 6, 33). Recently, azole-resistant $C$. albicans has become a clinical problem in AIDS patients with oropharyngeal candidiasis (OPC) and esophageal candidiasis $(11,24,31,34,35)$; and other Candida spp., such as Candida glabrata, Candida tropicalis, Candida parapsilosis, and Candida krusei, have emerged as clinically important pathogens $(5,6,30)$. Aspergillus spp. and Cryptococcus neoformans are also important pathogens which cause serious infections $(8,23,27)$. Although there has been an expansion in the number of antifungal agents available $(13,14)$, the treatments for fungal diseases remain unsatisfactory. Therefore, there is a need to search for novel antifungal agents that have novel modes of action and fewer side effects and that can be administered both orally and parenterally.

Sordarins are a novel class of antifungal compounds that act by selectively inhibiting the protein synthesis elongation step of fungi (9). It has been reported that sordarins interact with translation elongation factor 2 of fungi $(9,10)$ and large ribosomal subunit stalk rpP0 (12). This multiple interaction may explain the high degree of selectivity of this class of compounds

\footnotetext{
* Corresponding author. Mailing address: Biological Research Laboratories, Sankyo Co., Ltd., 2-58 Hiromachi 1-chome, Shinagawa-ku, Tokyo 140-8710, Japan. Phone: 81-3-3492-3131. Fax: 81-3-5436-8565. E-mail: ykamai@sankyo.co.jp.
}

between fungal and mammalian cells (12). Some pharmaceutical companies have reported that sordarin derivatives exhibit potent antifungal activities with relatively broad-spectrum activities in vitro and that some compounds exhibit good efficacies in vivo $(2,7,15,16,17,25,26)$. We also synthesized sordarin derivatives from zofimarin, a sordarin-related natural product which was isolated from the fungus Zopfiella marina (32). Chemical modification efforts led to R-135853 (Fig. 1), which was selected as a candidate for further evaluation $(1,21$, 22). In the present study, we investigated the in vitro antifungal activities of R-135853 against pathogenic fungi and its in vivo activities against experimental candidiasis in mice.

(This work was presented at the 42nd Interscience Conference on Antimicrobial Agents and Chemotherapy, San Diego, Calif., 27 to 30 September 2002 [T. Fukuoka, Y. Kamai, M. Kakuta, S. Kaneko, M. Arai, T. Uchida, T. Konosu, and S. Kuwahara, Abstr. 42nd Intersci. Conf. Antimicrob. Agents Chemother., abstr. F-824, 2002; T. Fukuoka, Y. Kamai, T. Shibayama, S. Kaneko, M. Arai, T. Uchida, T. Konosu, and S. Kuwahara, Abstr. 42nd Intersci. Conf. Antimicrob. Agents Chemother., abstr. F-825, 2002]. The code number RS-135853 used in those presentations is referred to as R-135853 in this paper.)

\section{MATERIALS AND METHODS}

Antifungal agents. R-135853 was synthesized by Sankyo Co., Ltd., for both the in vitro and the in vivo studies. For the in vitro study, fluconazole (FLC) and itraconazole (ITC) were extracted from commercial preparations purchased from Pfizer Pharmaceuticals, Inc. (Tokyo, Japan), and Janssen-Kyowa Co., Ltd. (Tokyo, Japan), respectively. Amphotericin B (AMB) was obtained commer- 


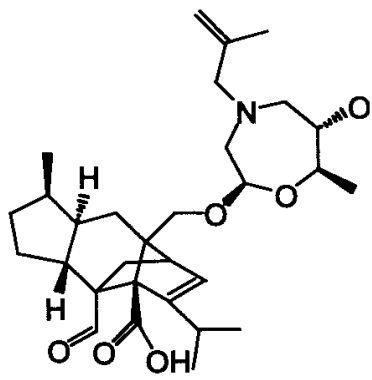

FIG. 1. Chemical structure of R-135853.

cially from Sigma Chemical Co. (St. Louis, Mo.). All the drugs for the in vitro study were dissolved in dimethyl sulfoxide (DMSO; Wako Pure Chemical Industries, Ltd., Osaka, Japan). A commercial preparation of FLC was used for the in vivo study. For oral administration in the experimental study of murine candidiasis, R-135853 was uniformly suspended in $0.5 \%$ sodium carboxymethyl cellulose (CMC; Kanto Chemical Co., Inc., Tokyo, Japan); for subcutaneous administration in the experimental study, R-135853 was dissolved in $0.1 \mathrm{~N} \mathrm{NaOH}$ (Kanto Chemical Co., Inc.)-25 mM Na $2 \mathrm{CO}_{3}$ (Iwai Chemicals Company, Tokyo, Japan) and FLC was dissolved in physiological saline (Otsuka Pharmaceutical Factory, Inc., Tokushima, Japan). For the pharmacokinetic analysis, R-135853 was uniformly suspended in $0.5 \%$ CMC- $10 \%$ DMSO for oral administration and was dissolved in 1\% Tween 80 (Kanto Chemical Co., Inc.)-10\% DMSO for intravenous administration.

Organisms. In the present study, we used C. albicans ATCC 24433, C. glabrata ATCC 90030, C. tropicalis ATCC 750, C. parapsilosis ATCC 22019, C. krusei TIMM3378, Candida guilliermondii ATCC 9390, C. neoformans ATCC 90112, Aspergillus fumigatus ATCC 26430, A. fumigatus SANK10569, and Aspergillus flavus ATCC 9643 for the investigation of antifungal spectrum of R-135853. We also used C. albicans SANK51486 and 2035B for the in vivo studies. The ATCC and TIMM strains were obtained from the American Type Culture Collection and Teikyo University Institute of Medical Mycology, respectively. The SANK strains had been stored at Sankyo Co., Ltd. C. albicans 2035B was provided by Scott G. Filler of Harbor-University of California, Los Angeles, Research and Education Institute. We also used clinical isolates of $C$. albicans, $C$. glabrata, $C$. tropicalis, C. parapsilosis, and C. neoformans provided by T. Oguri of Juntendo University Hospital, S. Kohno of Nagasaki University School of Medicine, and Scott G. Filler for the investigation of the MICs of R-135853. For the in vitro study, Candida spp. and C. neoformans were cultured on Sabouraud dextrose agar (SDA; Eiken Chemical Co., Ltd., Tokyo, Japan) and Aspergillus spp. were cultured on potato dextrose agar (Eiken Chemical Co., Ltd.). For the in vivo study, C. albicans SANK51486 and 2035B were cultured in YPG medium, which consisted of $0.5 \%$ yeast extract (Difco Laboratories, Detroit, Mich.), $1 \%$ peptone (Difco Laboratories), and 2\% glucose (Wako Pure Chemical Industries, Ltd.) overnight at $35^{\circ} \mathrm{C}$ with shaking.

In vitro susceptibility testing. The MICs for the test organisms were determined by the broth microdilution method described in NCCLS document M27-A2 (28) for Candida spp. and C. neoformans and NCCLS document M38-A (29) for Aspergillus spp. The MICs of R-135853 were defined as the lowest concentration that resulted in slight growth (approximately $90 \%$ inhibition) or the absence of growth at $48 \mathrm{~h}$.

Animals. Specific-pathogen-free male ddY mice (age, 4 weeks) were purchased from Japan SLC, Inc., Shizuoka, Japan, and were used for both the experimental candidiasis and the pharmacokinetic analyses. The mice were used for the experiments after an acclimation period of 6 days. In the experimental study of murine esophageal candidiasis, the mice were immunosuppressed by subcutaneous injection of $4 \mathrm{mg}$ of cortisone acetate (Tokyo Kasei Kogyo Co., Ltd., Tokyo, Japan) per mouse 2 days before, on the day of, and 3 days after inoculation. During the period of immunosuppression, the mice were given tetracycline hydrochloride $(0.5 \mathrm{mg} / \mathrm{ml}$ in drinking water; Achromycin V; Wyeth Lederle Japan, Ltd., Tokyo, Japan) for the prevention of bacterial infection. Mice were given food and water freely throughout the experiments. All animal experiments were carried out according to the guidelines provided by the Institutional Animal Care and Use Committee of Sankyo Co., Ltd. The experiments used five mice per group.

Efficacy against experimental murine hematogenous candidiasis. We used $C$. albicans strain SANK51486 in the experimental study of murine hematogenous candidiasis. The inoculum suspension of $2.5 \times 10^{6} \mathrm{cells} / \mathrm{ml}$ was prepared with
TABLE 1. Antifungal spectrum of R-135853

\begin{tabular}{|c|c|c|c|c|}
\hline \multirow{2}{*}{ Organism and strain } & \multicolumn{4}{|c|}{ MIC $(\mu \mathrm{g} / \mathrm{ml})$} \\
\hline & $\mathrm{R}-135853$ & FLC & ITC & AMB \\
\hline \multicolumn{5}{|l|}{ Candida albicans } \\
\hline ATCC 24433 & 0.016 & 0.25 & 0.016 & 0.12 \\
\hline SANK51486 ${ }^{a}$ & 0.016 & 0.25 & 0.016 & 0.12 \\
\hline $2035 \mathrm{~B}^{a}$ & 0.03 & 64 & 0.12 & 0.25 \\
\hline $\begin{array}{l}\text { Candida glabrata ATCC } \\
90030\end{array}$ & 0.5 & 4 & 0.12 & 0.12 \\
\hline $\begin{array}{l}\text { Candida tropicalis ATCC } \\
750\end{array}$ & 0.06 & 2 & 0.06 & 0.25 \\
\hline $\begin{array}{l}\text { Candida parapsilosis } \\
\text { ATCC } 22019\end{array}$ & 64 & 2 & 0.03 & 0.5 \\
\hline $\begin{array}{l}\text { Candida krusei } \\
\text { TIMM3378 }\end{array}$ & $>128$ & 32 & 0.06 & 0.25 \\
\hline $\begin{array}{l}\text { Candida guilliermondii } \\
\text { ATCC } 9390\end{array}$ & 0.5 & 2 & 0.03 & 0.06 \\
\hline $\begin{array}{l}\text { Cryptococcus neoformans } \\
\text { ATCC } 90112\end{array}$ & 0.12 & 4 & 0.016 & 0.12 \\
\hline \multicolumn{5}{|l|}{ Aspergillus fumigatus } \\
\hline ATCC 26430 & $>128$ & $>128$ & 0.5 & 0.25 \\
\hline SANK 10569 & $>128$ & $>128$ & 0.5 & 0.5 \\
\hline $\begin{array}{l}\text { Aspergillus flavus ATCC } \\
9643\end{array}$ & $>128$ & $>128$ & 0.25 & 0.5 \\
\hline
\end{tabular}

${ }^{a}$ Strains used for the in vivo studies.

sterile physiological saline. The mice were inoculated with $5.0 \times 10^{5}$ cells via the tail vein. For subcutaneous therapy, R-135853 was administered subcutaneously at 2,5 , and $8 \mathrm{~h}$ postinoculation at 2,10 , and $50 \mathrm{mg} / \mathrm{kg}$ of body weight $/$ dose. For oral therapy, R-135853 was administered orally at $2 \mathrm{~h}$ postinoculation (single administration) or at 2,5 , and $8 \mathrm{~h}$ postinoculation (administration three times a day) at 2,10 , and $50 \mathrm{mg} / \mathrm{kg} / \mathrm{dose}$. The control group received $0.2 \mathrm{ml}$ of the vehicle at 2,5 , and $8 \mathrm{~h}$ postinoculation by the same route by which R-135853 was administered. Efficacy was evaluated by determination of the viable cell counts in the kidneys. The mice were sacrificed at $24 \mathrm{~h}$ postinoculation, the kidneys were excised and homogenized in sterile physiological saline, and serial dilutions were cultured on SDA containing $10 \mu \mathrm{g}$ of chloramphenicol per $\mathrm{ml}$ at $35^{\circ} \mathrm{C}$ for 2 days. The viable cell counts in the kidneys were determined by counting the colonies on the SDA plates.

Efficacy against experimental murine esophageal candidiasis. Experimental murine esophageal candidiasis was induced by the same procedure by which experimental murine oropharyngeal candidiasis was induced, as reported previously (20). In this experiment, we used C. albicans strain 2035B. The inoculum suspension of $1.0 \times 10^{8}$ cells $/ \mathrm{ml}$ was prepared with sterile physiological saline. Before inoculation, the mice were anesthetized by intraperitoneal injection of $27.5 \mu \mathrm{g}$ of dimorpholamine (Theraptique; Eisai Co., Ltd., Tokyo, Japan), $219 \mu \mathrm{g}$ of xylazine (Bayer Yakuhin, Ltd., Osaka, Japan), and $1.28 \mathrm{mg}$ of pentobarbital sodium (Nembutal; Dainippon Pharmaceutical Co., Ltd., Osaka, Japan) per mouse. R-135853 was administered subcutaneously three times a day for 2 days starting at 3 days postinoculation (70,73, 76, 94, 97, and $100 \mathrm{~h}$ postinoculation) at 2,10 , and $50 \mathrm{mg} / \mathrm{kg} / \mathrm{dose}$. For the reference group, FLC was administered subcutaneously once a day for 2 days starting at 3 days postinoculation (70 and $94 \mathrm{~h}$ postinoculation) at $50 \mathrm{mg} / \mathrm{kg} / \mathrm{dose}$. The control group received $0.2 \mathrm{ml}$ of the vehicle for R-135853 by the same dosing regimen as that used for R-135853 administration. Efficacy was evaluated by determination of the viable cell counts in the esophagi. The mice were sacrificed at 5 days postinoculation, the esophagi were excised and homogenized in sterile physiological saline, and serial dilutions were cultured on SDA containing $10 \mu \mathrm{g}$ of chloramphenicol per $\mathrm{ml}$ at $35^{\circ} \mathrm{C}$ for 2 days. The viable cell counts in the esophagi were determined by counting the colonies on SDA plates.

Pharmacokinetic analysis. Mice received R-135853 orally at $20 \mathrm{mg} / \mathrm{kg}$ or intravenously at $2 \mathrm{mg} / \mathrm{kg}$. Mice $(n=3)$ were killed at $5,15,30,45,60,120$, and 180 min postadministration and blood samples were collected. R-135853 levels in plasma was measured by liquid chromatography-mass spectrometry; and the pharmacokinetic parameters of half-life in plasma, area under the concentrationtime curve (AUC) from time zero to infinity $\left(\mathrm{AUC}_{0-\infty}\right)$, total body clearance, volume of distribution, the maximum concentration in plasma $\left(C_{\max }\right)$, and the time to $C_{\max }\left(T_{\max }\right)$ were calculated by using WinNonlin software (Scientific 


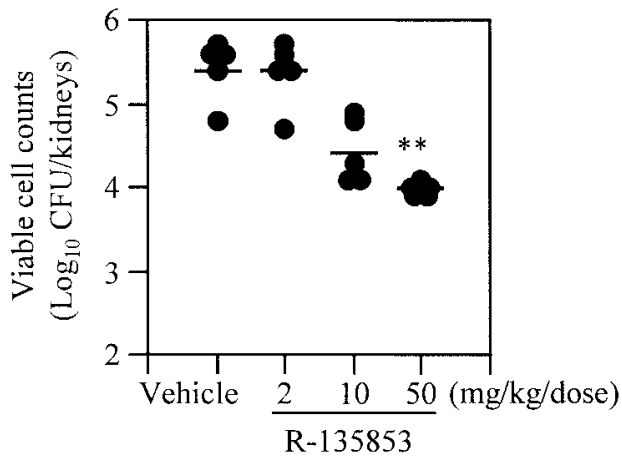

FIG. 2. Efficacy of R-135853 against experimental murine hematogenous candidiasis (subcutaneous therapy). Each circle and bar represents the result for an individual mouse and the mean value $(n=5)$, respectively. **, $P<0.01$ versus the results for the vehicle-treated control group by the nonparametric Dunnett test.

Consulting, Inc.). Oral bioavailability was determined by comparing the $\mathrm{AUC}_{0-\infty}$ values for the oral and intravenous routes of administration.

Statistical analysis. The viable cell counts in the kidneys and the esophagi of the control group and the treated groups were compared by the nonparametric Dunnett test. When the culture was sterile, the value for the detection limit was used for the statistical analysis. $P$ values below 0.05 were considered significant The SAS system for Windows (release 6.12; SAS Institute Inc.) was used for the analysis.

\section{RESULTS}

In vitro antifungal activity. Table 1 shows the spectrum of activities of R-135853 and other reference agents against various fungal strains and also shows the MICs of R-135853 for the strains used for the in vivo studies. R-135853 exhibited potent activities against $C$. albicans, $C$. glabrata, $C$. tropicalis, $C$. guilliermondii, and $C$. neoformans, with MICs ranging from 0.016 to $0.5 \mu \mathrm{g} / \mathrm{ml}$. However, R-135853 exhibited weak activity against $C$. parapsilosis and no activity against $C$. krusei or $A s$ pergillus spp. Table 2 shows the MICs of R-135853 and other reference agents for clinical yeast isolates. Table 2 shows the results for $C$. albicans separately for FLC-susceptible (FLC-S) strains (FLC MICs, $\leq 8 \mu \mathrm{g} / \mathrm{ml}$ ) and FLC-susceptible dose-dependent (FLC-S-DD) and FLC-resistant (FLC-R) strains (FLC MICs, $\geq 16 \mu \mathrm{g} / \mathrm{ml}$ ), according to the guidelines of NCCLS document M27-A2 (28). R-135853 exhibited potent activities against $C$. albicans (FLC-S), C. glabrata, C. tropicalis, and $C$. neoformans, with MICs at which $90 \%$ of isolates are inhibited $\left(\mathrm{MIC}_{90} \mathrm{~s}\right)$ of $0.03,1,0.5$, and $0.5 \mu \mathrm{g} / \mathrm{ml}$, respectively, but weak activity against $C$. parapsilosis, with an $\mathrm{MIC}_{90}$ of 128 $\mu \mathrm{g} / \mathrm{ml}$. R-135853 also exhibited potent activities against the FLC-S-DD and FLC-R strains of $C$. albicans (MIC range, 0.03 to $0.06 \mu \mathrm{g} / \mathrm{ml}$ ), which were comparable to those against the FLC-S strains.

Efficacy against experimental murine hematogenous candidiasis (subcutaneous therapy). Figure 2 shows the efficacy of subcutaneous administration of R-135853 against experimental murine hematogenous candidiasis induced by $C$. albicans strain SANK51486. R-135853 exhibited dose-dependent efficacy against the infection and at $50 \mathrm{mg} / \mathrm{kg} / \mathrm{dose}$ significantly $(P<0.01)$ reduced the viable cell counts in the kidneys.

Efficacy against experimental murine hematogenous candidiasis (oral therapy). In the study for oral therapy for exper-
TABLE 2. In vitro antifungal activity of R-135853 against clinical yeast isolates

\begin{tabular}{|c|c|c|c|}
\hline \multirow{2}{*}{ Organism (no. of isolates) and agent } & \multicolumn{3}{|c|}{$\operatorname{MIC}(\mu \mathrm{g} / \mathrm{ml})$} \\
\hline & Range & $50 \%$ & $90 \%$ \\
\hline \multicolumn{4}{|l|}{ Candida albicans, FLC-S ${ }^{a}(22)$} \\
\hline R-135853 & $0.016-0.06$ & 0.03 & 0.03 \\
\hline FLC & $0.25-8$ & 1 & 2 \\
\hline ITC & $0.008-0.03$ & 0.016 & 0.03 \\
\hline AMB & $0.12-0.25$ & 0.12 & 0.12 \\
\hline \multicolumn{4}{|l|}{$\begin{array}{l}\text { Candida albicans, FLC-S-DD and } \\
\text { FLC-R }^{b}(8)\end{array}$} \\
\hline $\mathrm{R}-135853$ & $0.03-0.06$ & $-^{c}$ & - \\
\hline FLC & $16-128$ & - & - \\
\hline ITC & $0.03-0.12$ & - & - \\
\hline AMB & $0.12-0.25$ & - & - \\
\hline \multicolumn{4}{|l|}{ Candida glabrata (15) } \\
\hline R-135853 & $0.5-1$ & 0.5 & 1 \\
\hline FLC & $1-16$ & 8 & 16 \\
\hline ITC & $0.03-0.5$ & 0.12 & 0.25 \\
\hline AMB & $0.06-0.12$ & 0.12 & 0.12 \\
\hline \multicolumn{4}{|l|}{ Candida tropicalis (15) } \\
\hline $\mathrm{R}-135853$ & $0.016-0.5$ & 0.25 & 0.5 \\
\hline FLC & $0.25-4$ & 1 & 2 \\
\hline ITC & $0.008-0.12$ & 0.03 & 0.12 \\
\hline $\mathrm{AMB}$ & $0.06-0.25$ & 0.12 & 0.12 \\
\hline \multicolumn{4}{|l|}{ Candida parapsilosis (15) } \\
\hline $\mathrm{R}-135853$ & $2-128$ & 64 & 128 \\
\hline FLC & $0.5-4$ & 1 & 2 \\
\hline ITC & $0.016-0.25$ & 0.03 & 0.03 \\
\hline AMB & $0.03-0.25$ & 0.25 & 0.25 \\
\hline \multicolumn{4}{|l|}{ Cryptococcus neoformans (15) } \\
\hline $\mathrm{R}-135853$ & $0.25-1$ & 0.25 & 0.5 \\
\hline FLC & $1-16$ & 4 & 16 \\
\hline ITC & $0.016-0.12$ & 0.06 & 0.12 \\
\hline AMB & $0.06-0.25$ & 0.12 & 0.12 \\
\hline
\end{tabular}

${ }^{a}$ FLC MICs, $\leq 8 \mu \mathrm{g} / \mathrm{ml}$.

${ }^{b}$ FLC MICs, $\geq 16 \mu \mathrm{g} / \mathrm{ml}$.

${ }^{c}$ - , not determined.

imental murine hematogenous candidiasis, we examined the efficacy of dose administration once and three times a day (Fig. $3)$. As was the case with the results of the study of subcutaneous therapy, the oral administration of R-135853 exhibited dose-dependent efficacy against the infection after administration both once and three times a day. R-135853 at $50 \mathrm{mg} / \mathrm{kg} /$ dose significantly $(P<0.001)$ reduced the viable cell counts in the kidneys by administration three times a day.

Efficacy against experimental murine esophageal candidiasis induced by FLC-resistant $\boldsymbol{C}$. albicans. Figure 4 shows the efficacy of subcutaneous administration of R-135853 against experimental murine esophageal candidiasis induced by FLCresistant strain $C$. albicans 2035B. R-135853 exhibited dosedependent efficacy against the infection and reduced the viable cell counts in the esophagi significantly when it was administered at 10 and $50 \mathrm{mg} / \mathrm{kg} / \mathrm{dose}(P<0.05$ and $P<0.001$, respectively). Notably, R-135853 eradicated $C$. albicans from the esophagi of one and four of five mice at 10 and $50 \mathrm{mg} / \mathrm{kg} /$ dose, respectively. On the other hand, FLC did not reduce the 


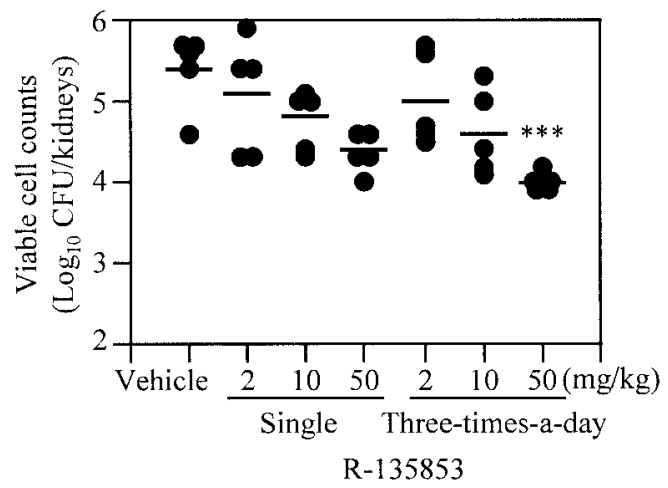

FIG. 3. Efficacy of R-135853 against experimental murine hematogenous candidiasis after administration once and three times a day (oral therapy). Each circle and bar represents the result for an individual mouse and the mean value $(n=5)$, respectively. $* * *, P<0.001$ versus the results for the vehicle-treated control group by the nonparametric Dunnett test.

viable cell counts significantly, even when it was administered at $50 \mathrm{mg} / \mathrm{kg} / \mathrm{dose}$.

Pharmacokinetics. Table 3 shows the values of the pharmacokinetic parameters after oral administration of R-135853 at $20 \mathrm{mg} / \mathrm{kg}$ and intravenous administration of R-135853 at 2 $\mathrm{mg} / \mathrm{kg}$.

\section{DISCUSSION}

Sordarins belong to a new class of antifungal agents with a novel mechanism of action $(9,10)$. In this study we evaluated the in vitro and in vivo activities of R-135853, a novel sordarin derivative possessing a 1,4-oxazepane ring moiety. R-135853 exhibited potent in vitro activities against $C$. albicans, including FLC-resistant strains; C. glabrata; $C$. guilliermondii; and $C$. neoformans. On the other hand, R-135853 exhibited weak or no activity against $C$. parapsilosis, $C$. krusei, and Aspergillus spp. These in vitro characteristics of R-135853 are similar to those of other sordarins reported previously $(16,17)$. It is remarkable that R-135853 exhibited potent activities against $C$. albicans, whether or not the strains showed resistance to FLC. C. albicans is a key yeast pathogen, and FLC-resistant $C$. albicans has become a clinical problem in AIDS patients with $\mathrm{OPC}(24,31$, $34,35)$. Therefore, we focused on $C$. albicans for the in vivo evaluation of R-135853.

We examined the in vivo efficacy of R-135853 against experimental murine hematogenous candidiasis. R-135853 exhibited good dose-dependent efficacy against the infection when it was administered subcutaneously, and similarly, it also exhibited good efficacy when it was administered orally. It was demonstrated that R-135853 was highly absorbed by oral administration in mice $(63 \%$ at $20 \mathrm{mg} / \mathrm{kg})$. The good in vivo efficacy reflected this high level of oral bioavailability. The fact that R-135853 showed efficacy when it was administered orally suggests that R-135853 could be used in formulations for both oral and parenteral use. This is an important attribute, because R-135853 can be used for parenteral-to-oral step-down therapy. In reports regarding other sordarins, it was shown that drugs of this class have short half-lives in plasma in experimental animals $(2,3,12)$. It was demonstrated that the half-life of

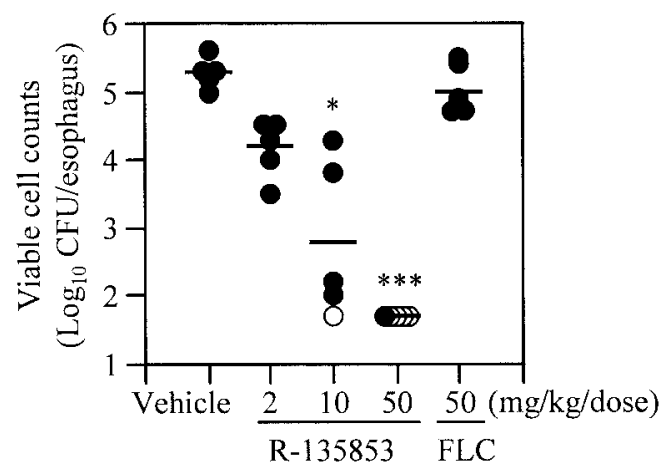

FIG. 4. Efficacy of R-135853 against experimental murine esophageal candidiasis induced by FLC-resistant $C$. albicans. Each circle represents the result for an individual mouse. Closed circles, results above the detection limit; open circles, results below the detection limit. Each bar represents the mean value $(n=5)$. $*, P<0.05$ versus the results for the vehicle-treated control group by the nonparametric Dunnett test; ***, $P<0.001$ versus the results for the vehicle-treated control group by the nonparametric Dunnett test.

$\mathrm{R}-135853$ in plasma was similarly short in mice $(1.1$ and $0.47 \mathrm{~h}$ after administration at $20 \mathrm{mg} / \mathrm{kg}$ orally and $2 \mathrm{mg} / \mathrm{kg}$ intravenously, respectively). However, we demonstrated that R135853 exhibits dose-dependent efficacy even after a single administration, although the efficacy was somewhat weaker than that by administration three times a day. Aviles et al. (2) reported that the AUC is the parameter most predictive of the efficacy of sordarins in a pharmacokinetic-pharmacodynamic study with mice. A pharmacokinetic-pharmacodynamic study with R-135853 is also needed to investigate the relationships between the pharmacokinetic-pharmacodynamic parameters and efficacy.

We next examined the in vivo efficacy of R-135853 against experimental murine esophageal candidiasis induced by FLCresistant $C$. albicans. FLC did not exhibit significant efficacy in this model, even when it was administered at $50 \mathrm{mg} / \mathrm{kg} / \mathrm{dose}$. Although FLC was administered once daily in this experiment, it was previously demonstrated (19) that this FLC dosing regimen is a proper means of achieving a good correlation between in vitro activity and efficacy in the murine OPC model, which is very similar to the esophageal candidiasis model used in the present study. In this model, R-135853 also exhibited good dose-dependent efficacy and eradicated C. albicans from the esophagi of one and four of five mice when it was administered at 10 and $50 \mathrm{mg} / \mathrm{kg} / \mathrm{dose}$, respectively. In the experimental models of hematogenous candidiasis and esophageal

TABLE 3. Pharmacokinetic parameters for R-135853 in mice

\begin{tabular}{lcc}
\hline \multicolumn{1}{c}{ Parameter } & $\begin{array}{c}\text { Oral dose } \\
(20 \mathrm{mg} / \mathrm{kg})\end{array}$ & $\begin{array}{c}\text { Intravenous dose } \\
(2 \mathrm{mg} / \mathrm{kg})\end{array}$ \\
\hline Half-life $(\mathrm{h})$ in plasma & 1.1 & 0.47 \\
$\mathrm{AUC}_{0-\infty}(\mu \mathrm{g} \cdot \mathrm{h} / \mathrm{ml})$ & 3.19 & 0.509 \\
Total body clearance (liters $/ \mathrm{h} / \mathrm{kg})$ & $-^{a}$ & 3.93 \\
Distribution volume (liters $/ \mathrm{kg})$ & - & 1.84 \\
$T_{\max }(\mathrm{h})$ & 0.25 & - \\
$C_{\max }(\mu \mathrm{g} / \mathrm{ml})$ & 2.32 & - \\
Bioavailability $(\%)$ & 62.7 & - \\
\hline
\end{tabular}

${ }^{a}$ - , not determined 
candidiasis, as the intervals between the time of administration of the last dose and the time of killing were somewhat prolonged (16 to $24 \mathrm{~h}$ ), it is possible that differences in the viable cell counts between the groups might be obscured to some extent by regrowth after administration of the last doses. However, we think that such an interval has little influence on the interpretation of the results, because the growth of the organisms was relatively slow in these infection models (results of a preliminary study; data not shown).

In conclusion, the results of the present study suggest that $\mathrm{R}-135853$ is a promising compound, in particular, for the treatment of disseminated or mucosal infections induced by $C$. albicans, including FLC-resistant strains. The development of $\mathrm{R}-135853$ is in the preclinical stage; and further investigations, such as pharmacokinetic-pharmacodynamic and toxicity studies, are needed.

\section{ACKNOWLEDGMENTS}

We thank T. Oguri of Juntendo University Hospital, S. Kohno of the Nagasaki University School of Medicine, and Scott G. Filler of the Harbor-University of California, Los Angeles, Research and Education Institute for providing us with clinical yeast isolates.

\section{REFERENCES}

1. Arai, M., T. Harasaki, T. Fukuoka, S. Kaneko, and T. Konosu. 2002. Synthesis and evaluation of novel pyrrolidinyl sordaricin derivatives as antifungal agents. Bioorg. Med. Chem. Lett. 19:2733-2736.

2. Aviles, P., C. Falcoz, R. San Roman, and D. Gargallo-Viola. 2000. Pharmacokinetics-pharmacodynamics of a sordarin derivative (GM237354) in a murine model of lethal candidiasis. Antimicrob. Agents Chemother. 44:23332340.

3. Aviles, P., A. Pateman, R. San Roman, M. J. Guillen, F. Gomez de las Heras, and D. Gargallo-Viola. 2001. Animal pharmacokinetics and interspecies scaling of sordarin derivatives following intravenous administration. Antimicrob. Agents Chemother. 45:2787-2792.

4. Banerjee, S. N., T. G. Emori, D. H. Culver, R. P. Gaynes, W. R. Jarvis, T. Horan, J. R. Edwards, J. Tolson, T. Henderson, and W. J. Martone. 1991 Secular trends in nosocomial primary bloodstream infections in the United States, 1980-1989. National Nosocomial Infections Surveillance System. Am. J. Med. 91:86S-89S.

5. Barchiesi, F., A. M. Tortorano, L. F. Di Francesco, M. Cogliati, G. Scalise, and M. A. Viviani. 1999. In-vitro activity of five antifungal agents against uncommon clinical isolates of Candida spp. J. Antimicrob. Chemother. 43: 295-299.

6. Beck-Sague, C. M., and W. R. Jarvis. 1993. Secular trends in the epidemiology of nosocomial fungal infections in the United States. National Nosocomial Infections Surveillance System. J. Infect. Dis. 167:1247-1251.

7. Clemons, K. V., and D. A. Stevens. 2000. Efficacies of sordarin derivatives GM193663, GM211676, and GM237354 in a murine model of systemic coccidioidomycosis. Antimicrob. Agents Chemother. 44:1874-1877.

8. Denning, D. W. 1998. Invasive aspergillosis. Clin. Infect. Dis. 26:781-803.

9. Dominguez, J. M., V. A. Kelly, O. S. Kinsman, M. S. Marriott, F. Gomez de las Heras, and J. J. Martin. 1998. Sordarins: a new class of antifungals with selective inhibition of the protein synthesis elongation cycle in yeasts. Antimicrob. Agents Chemother. 42:2274-2278.

10. Dominguez, J. M., and J. J. Martin. 1998. Identification of elongation factor 2 as the essential protein targeted by sordarins in Candida albicans. Antimicrob. Agents Chemother. 42:2279-2283.

11. Franz, R., S. L. Kelly, D. C. Lamb, D. E. Kelly, M. Ruhnke, and J. Morschhäuser. 1998. Multiple molecular mechanisms contribute to a stepwise development of fluconazole resistance in clinical Candida albicans strains. Antimicrob. Agents Chemother. 42:3065-3072.

12. Gargallo-Viola, D. 1999. Sordarins as antifungal compounds. Curr. Opin. Anti-Infect. Investig. Drugs 1:297-305.

13. Georgopapadakou, N. H., and T. J. Walsh. 1994. Human mycoses: drugs and targets for emerging pathogens. Science 264:371-373.
14. Georgopapadakou, N. H., and T. J. Walsh. 1996. Antifungal agents: chemotherapeutic targets and immunologic strategies. Antimicrob. Agents Chemother. 40:279-291.

15. Graybill, J. R., L. Najvar, A. Fothergill, R. Bocanegra, and F. Gomez de las Heras. 1999. Activities of sordarins in murine histoplasmosis. Antimicrob. Agents Chemother. 43:1716-1718.

16. Herreros, E., M. J. Almela, S. Lozano, F. Gomez de las Heras, and D. Gargallo-Viola. 2001. Antifungal activities and cytotoxicity studies of six new azasordarins. Antimicrob. Agents Chemother. 45:3132-3139.

17. Herreros, E., C. M. Martinez, M. J. Almela, M. S. Marriott, F. Gomez de las Heras, and D. Gargallo-Viola. 1998. Sordarins: in vitro activities of new antifungal derivatives against pathogenic yeasts, Pneumocystis carinii, and filamentous fungi. Antimicrob. Agents Chemother. 42:2863-2869.

18. Hoffman, H. L., E. J. Ernst, and M. E. Klepser. 2000. Novel triazole antifungal agents. Exp. Opin. Investig. Drugs 9:593-605.

19. Kamai, Y., M. Kubota, T. Fukuoka, Y. Kamai, N. Maeda, T. Hosokawa, T. Shibayama, K. Uchida, H. Yamaguchi, and S. Kuwahara. 2003. Efficacy of CS-758, a novel triazole, against experimental fluconazole-resistant oropharyngeal candidiasis in mice. Antimicrob. Agents Chemother. 47:601-606.

20. Kamai, Y., M. Kubota, Y. Kamai, T. Hosokawa, T. Fukuoka, and S. G. Filler. 2001. New model of oropharyngeal candidiasis in mice. Antimicrob. Agents Chemother. 45:3195-3197.

21. Kaneko, S., M. Arai, T. Uchida, T. Harasaki, T. Fukuoka, and T. Konosu. 2002. Synthesis and evaluation of $N$-substituted 1,4-oxazepanyl sordaricins as selective fungal EF-2 inhibitors. Bioorg. Med. Chem. Lett. 12:1705-1708.

22. Kaneko, S., T. Uchida, S. Shibuya, T. Honda, I. Kawamoto, T. Harasaki, T. Fukuoka, and T. Konosu. 2002. Synthesis of sordaricin analogues as potent antifungal agents against Candida albicans. Bioorg. Med. Chem. Lett. 12: 803-806.

23. Latge, J. P. 1999. Aspergillus fumigatus and aspergillosis. Clin. Microbiol. Rev. 12:310-350.

24. Law, D., C. B. Moore, H. M. Wardle, L. A. Ganguli, M. G. Keaney, and D. W. Denning. 1994. High prevalence of antifungal resistance in Candida spp. from patients with AIDS. J. Antimicrob. Chemother. 34:659-668.

25. Martinez, A., S. Ferrer, I. Santos, E. Jimenez, J. Sparrowe, J. Regadera, F. Gomez de las Heras, and D. Gargallo-Viola. 2001. Antifungal activities of two new azasordarins GW471552 and GW471558, in experimental models of oral and vulvovaginal candidiasis in immunosuppressed rats. Antimicrob. Agents Chemother. 45:3304-3309.

26. Martinez, A., J. Regadera, E. Jimenez, I. Santos, and D. Gargallo-Viola. 2001. Antifungal efficacy of GM237354, a sordarin derivative, in experimental oral candidiasis in immunosuppressed rats. Antimicrob. Agents Chemother. 45:1008-1013

27. Mitchell, T. G., and J. R. Perfect. 1995. Cryptococcosis in the era of AIDS100 years after the discovery of Cryptococcus neoformans. Clin. Microbiol. Rev. 8:515-548.

28. National Committee for Clinical Laboratory Standards. 2002. Reference method for broth dilution antifungal susceptibility testing of yeasts. Approved standard M27-A2. National Committee for Clinical Laboratory Standards, Wayne, Pa.

29. National Committee for Clinical Laboratory Standards. 2002. Reference method for broth dilution antifungal susceptibility testing of filamentous fungi. Approved standard M38-A. National Committee for Clinical Laboratory Standards, Wayne, $\mathrm{Pa}$.

30. Nguyen, M. H., J. E. Peacock, Jr., A. J. Morris, D. C. Tanner, M. L. Nguyen, D. R. Snydman, M. M. Wagener, M. G. Rinaldi, and V. L. Yu. 1996. The changing face of candidemia: emergence of non-Candida albicans species and antifungal resistance. Am. J. Med. 100:617-623.

31. Odds, F. C. 1996 . Resistance of clinically important yeasts to antifungal agents. Int. J. Antimicrob. Agents 6:145-147.

32. Ogita, T., T. Hayashi, A. Sato, and W. Furutani. Feb. 1987. Japanese patent $62,040,292$.

33. Pfaller, M. A., S. A. Messer, R. J. Hollis, R. N. Jones, G. V. Doern, M. E. Brandt, and R. A. Hajjeh. 1999. Trends in species distribution and susceptibility to fluconazole among blood stream isolates of Candida species in the United States. Diagn. Microbiol. Infect. Dis. 33:217-222.

34. Redding, S., J. Smith, G. Farinacci, M. Rinaldi, A. Fothergill, J. RhineChalberg, and M. Pfaller. 1994. Resistance of Candida albicans to fluconazole during treatment of oropharyngeal candidiasis in a patient with AIDS: documentation by in vitro susceptibility testing and DNA subtype analysis. Clin. Infect. Dis. 18:240-242.

35. Rex, J. H., M. G. Rinaldi, and M. Pfaller. 1995. Resistance of Candida species to fluconazole. Antimicrob. Agents Chemother. 39:1-8. 